\title{
HEGEMONI DALAM NOVEL SEUMPAMA MATAHARI KARYA ARAF́AT NUR
}

\author{
Oleh \\ Andu Purwanto \\ (Pendidikan Bahasa dan Sastra Indonesia, Fakultas Keguruan dan Ilmu Pendidikan, Universitas PGRI \\ Adi Buana Surabaya) \\ andupurwanto@gmail com \\ Sunu Catur Budiono \\ (Pendidikan Bahasa dan Sastra Indonesia, Fakultas Keguruan dan Ilmu Pendidikan, Universitas PGRI \\ Adi Buana Surabaya) \\ Sunucatur85@gmail com
}

\begin{abstract}
This study aims to describe cultural hegemony, ideology of leaders, intellectuals, state and leadership in a Novel Like the Sun works Arafat Nur. This research is descriptive qualitative. Date in the research is text - text in the form of phrase, sentences or paragraphs. As for date collection techniques in this study is the technique of reading and engineering notes.

Novel Like The Sun creation Arafat Nur is one of the works of Literature that rasises social problems and cultural issues. Novel This novel contains the conflict that occurred in Aceh. Interesting stuff from novel is raised a social and cultural conflict especially in begemony.

The results of this study indicate the existence of class hegemony in power in Aceh society, a culture that includes public trust society. Javanese culture or custom which begemony directly and indirectly, ideology figures that reflect on behavior, intellectuals are seen in the father as a helper. The state of the hegemonious civil society by the rulers, the leadership who leads or invites his friend to be careful. Conclusions and suggestions are given for research this can be useful for readers and other researchers in the development of theory and methods especially in field of Indonesian language and literature.

Keywords : Hegemony, Ideology, Culture, intellectuals, and Leadership

\section{PENDAHULUAN}

Banyak seni karya tulis yang dibuat darı kreativitas seseorang yang menghasilkan sebuah karya sastra, dan dinikmati oleh semua kalangan masyarakat.Salah satu bentuk karya - sastra adalah novel. Novel adalah karangan prosa yang panjang. mengandung mangkaian cerita kehidupan seseorang dengan orang-orang di sekitarmya serta menonjolkan watak dan sifat setiap pelaka Cerita dalam novel dimulai dari peristiwa atau kejadian terpenfing yane dalami oleh tokoh cerita, yang kelak mengubah nasib kehidupannya Novel menupakan bentuk karya sastra yang sekaligus disebut fiksi. Fiksi berarti cerita rekan dan Whayalan $\mathrm{Hal}$ ini disebabkan fiksı merupakan karya naratif yang isinya tidak menyarankan pada kebenaran sejarah.

Dalam kebidupan manusta akan selalu ada yang memerintah das diperintah yang keenudian

menjadi sebuah peaindasan apabila perintah yang diberikan menjuras pada paksaan yang menghanuskan untuk dikkuti, bayaimanapun bentuk perintah yang diberikan. Kelompok sosial yang kemudian memimpin tersebut, melaksanakan kepemimpinan harus mendapatkan kekuasaan agar menjadi kekuasaan yang dominan dan harus meneruskan untuk memimpin, yang kemudian disebut oleh Gramci sebagai hegemoni.

Hegemoni adalah sebuah mantai kemenanigan yang. didapat melalui mekanisme konsensus ketimbang melalui penindasan terhadap klas sosial lainnya (nezer patria \& andi anf 2015:120).Hegernoni gramci membuka dimensı baru dalam studi sosiologis mengenai kesusastraan. Kesusatraan tidak lagi dipandang semati-mati sebagai gejala kedua yang tergantung dan ditentukan oleh masyarakat kelas sebagai infastruktumya.
\end{abstract}


melainkan dipahami sebagai kekuatan sosial, politik, dan kultural yang berdiri sendiri dan memiliki sistem, meskipun tidak terlepas dari infastrukturnya (Faruk 2014 : 154). Kultur atau kebudayaan sebagai sebuah organisasi untuk pencapaian lebih baik untuk diri-sendiri atau dalam hal kepemimpinan.

Pengembangkan gagasan tentang kepemimpinan dan pelaksanaannya sebagai syarat untuk memperoleh kekuasaan negara ke dalam konsep yang disebutnya hegemoni.Bagi gramsci hegemoni merupakan hubungan antara kelas dengan kekuatan sosial lainnya.Kepemimpinan hegemoni adalah kepemimpinan yang dilakukan secara konsensus yaitu persetujuan bersama, baik secara moral maupun intelektual yang berkaitan dengan kesadaran, pola pikir dan pemahaman masyarakat serta norma-norma yang berlaku (Kurniawan 2012:74).

Setiap pengarang tentu memiliki pandangan sendiri-sendiri mengenai keadaan sosial dalam masyarakat, salah satunya Arafat Nur seorang sastrawan berkebangsaan Indonesia.Arafat Nur Lahir di Lubuk Pakam (Deli Serdang-sumut) Aceh.Sejak muda dia sudah mengakrabi dunia sastra, terutama puisi dan prosa.Mengawali debutnya sebagai penulis pada tahun 1997. Pada saat itu, karyanya mulai terpublikasikan di sejumlah media massa, baik yang terbit di Sumatera Utara dan Nangroe Aceh Darussalam maupun Jakarta. Arafat Nur juga menjalani profesi sebagai jurnalis.Karya Arafat Nur begitu membumi, karya-karyanya banyak mengangkat tentang kehidupan masyarakat Aceh.Kemampuanya menghasilkan karya berkualitas, telah mengantarkan Arafat Nur memenangi beberapa penghargaan.Dua karya sastra yang membesarkan namanya yaitu berjudul "Novel Lampuki" dan "Novel Tanah Surga Merah".
Selain dua karya tersebut, masih ada novel lainnya yang berjudul Tempat paling sunyi dan burung terbang di kelam malam.Arafat Nur juga banyak menulis artikel yang masuk dalam media cetak dan masuk dalam beberapa cerpen.Novel-novel lain yang telah ditulis diantaranya Meutia Lon Sayang, Cinta Mahasunyi, Percikan Darah di Bunga.Dan novel Seumpama Matahari di tulis berdasarkan catatan seorang gerilyawan Thaleh Loh Angen, Kombatan Gerakan Aceh Merdeka.Semula Thayeb hendak memusnahkan catatannya, tetapi berhasil diselamatkan oleh Arafat Nur.

Penelitian ini membahas tentang hegemoni yang terdapat dalam novel Seumpama Mataharikarya Arafat Nur yang menggambarkan realitas sekelompok pemberontak yang memimpin rakyat Aceh dan berhianat kepada Tentara pemerintah.Sebutan penghianat oleh tentara pemerintah yaitu "pemberontak". Kehidupan seperti itu mungkin banyak dijumpai pada zaman dahulu, namun tidak banyak orang melihat dengan "sisi terbuka" bahwa keadaan tersebut menimbulkan dampak tertentu bagi orang-orang yang mengalami atau menjadi korban penindasan pada waktu itu, dampak terasa sampai sekarang. Kepemimpinan ini terjadi ketika masyarakat Aceh mengalami penindasan yang amat pedih bahkan korban berjatuhan.

Dipilihnya novel Seumpama Matahari karya Arafat Nur menggunakan fokus kajian hegemoni karena pengarang menggambarkan dengan jelas realitas kehidupan sosial mengenai hegemoni, penggambaran kultural mengenai pemberontak yang berkonflik dengan tentara pemerintah demi mempertahankan kepemimpinannya. Cerminan kepemimpinan yang jelas tergambar saat pemberontak rela menghadapi maut bahkan menghadapi kisah cinta mereka dengan peperangan. 


\section{METODE PENELITIAN}

Pendekatan adalah wilayah atau ruang lingkup sebuah penelitian, wilayah ini berhubungan dengan aspek-aspek yang akan diungkap dalam penelitian, pendekatan akan membingkai objek apa saja yang mungkin diungkap dalam penelitian. Dalam penelitian ini peneliti menggunakan jenis penelitian deskriptif kualitatif.Karena hasil yang diperoleh berupa data deskrips berupa kata, kalimat atau paragraf.Pada penelitian ini, peneliti menggunakan teori hegemoni.Data penelitian ini adalah berupa kata, kalimat atau paragraf dalam novel seumpama matahari yang mengandung kajian hegemoni.pengumpulan data merupakan langkah yang paling strategis dalam penelitian, karena tujuan utama dari penelitian adalah mendapatkan data. Tanpa mengetahui teknik pengumpulan data, maka peneliti tidak akan mendapatkan data yang memenuhi standart data yang ditetapkan (Sugiono, 2012:224). Adapun tekniknya yaitu Membaca secara keseluruhan novel Seumpama Matahari karya Arafat Nur, Menggaris bawahi setiap kutipan-kutipan yang dijadikan data agar jelas dan sesuai dengan permasalahan yang diteliti, Mengklasifikasi data-data yang berasal dari kutipan - kutipan yang telah digaris bawahi sesuai dengan teori yang digunakan. Analisis data yang digunakan dalam penelitian ini adalah deskriptif kualitatif. Teknik ini dilakukan dengan cara Mencermati kembali data yang terkumpul dalam novel Seumpama Matahari karya Arafat Nur, Menganalisis data yang telah terkumpul, dan Menarik kesimpulan.

\section{HASIL DAN PEMBAHASAN}

Hegemoni dalam novel Seumpama Mataharikarya Arafat Nur.Dapat dilihat dari berbagai enam aspek diantaranya (1) hegemoni klas berkuasa, (2) ideologi tokoh,
(3) budaya, (4) kaum intelektual, (5) negara, dan (6) kepemimpinan.

(1) Hegemoni klas berkuaasa

Hegemoni adalah menguasai dengan kepemimpinan moral dan intelektual dimana kekuatan hanyalah instrument untuk menjaga stabilitas kekuasaan terhadap ideologi, moral, dan kultur. Yang menunjukkan hegemoni klas berkuasa terlihat pada kutipan berikut.

Kami bertiga tercenung. Tidak tahu apa yang bakalan terjadi di masa mendatang. Tetapi, sesuatu pasti terjadi. Aku harus siap-siap menghadapi segala kemungkinan. Perang selalu mengancam keselamatan jiwa. Jika tidak dari musuh, bisa datang dari teman sendiri, begitulah(Nur, 2017:99).

Dalam kutipan data di atas, terlihat jelas dari bentuk penggambaran hegemoni kelas berkuasa dengan pemikiran dari tiga pejuang. Dalam hal ini, tiga pejuang sedang terenung membicarakan atau memikirkan tentang sesuatu yang akan terjadi di masa depan atau masa selanjutnya. Terlihat hegemoni kelas berkuasa yang ada, di mana tiga pejuang harus siap dan waspada terhadap segala sesuatu yang akan mengancam mereka baik dari perang sama musuh atau dari teman mereka sendiri. Jika bukan mereka sendiri lalu siapa yang akan menjadi pelindung diri.

(2) Ideologi tokoh

Ideologi tokoh lebih sekadar sistem ide, ideologi bukanlah fantasi perorangan bisa juga dari masyarakat. Ideologi mampu memberikan berbagai aturan bagi tindakan praktik serta perilaku moral manusia. Dalam novel Seumpama Matahari karya Arafat Nur, bentuk ideologi dapat dilihat dari tokoh dalam cerita. Ideologi dapat diketahui dengan tingkah laku dan bentuk karakter tokoh dalam melakukan sesuatu hal. Dapat dilihat dalam kutipan berikut:

Tentu aku bingung. Aku tidak menduga dia berani menyuruhku begitu. Sungguh, 
ini betul-betul diluar dugaanku. Tetapi, begitulah kenyataannya. Anehnya, aku juga tidak bisa menolaknya. Bahkan aku bagai tak terperdaya, tanganku bergerakgerak menyisir rambutnya. Kesannya seperti sedang menyisir rambut seorang adik perempuan. Padahal aku sedang menyisirrambut gadis....yang sedang mengalami gangguan urat kepala(Nur, 2017:36).

Dalam kutipan di atas, menggambarkan ideologi yang dianut oleh tokoh $\mathrm{Aku}$ bingung dan tak terperdaya dengan seoarang perempuan yang menyuruh untuk menyisir rambutnya dan tak bisa menolaknya. Tokoh aku membayangkan yang disisir itu rambut adiknya dan menganggap perempuan tersebut kurang waras karena mereka baru saja bertemu berani menyuruhnya. Pada tokoh aku terhegemoni dengan suruhan perempuan yang ditemuinya.

(3) Budaya

kebudayaan sebagai satu kekuatan material yang mempunyai dampak praktis dan berbahaya bagi masyarakat. Gramsci merumuskan mengenai hubungan antara kelas dan kebudayaan dalam berbagai konteks dan membuat tiga tantangan. Pertama, tantangan terhadap tradisi idealis liberal yang memahami budaya sebagai sesuatu yang hakikatnya politik atau sebagai persoalan roh. Kedua, pada konsep marxis yang mereduksi kebudayaan semata-mata sebagai refleksi dari dasar ekonomi masyarakat. Ketiga, kebudayaan terhadap zamannya sendiri untuk mentransformasikan negara sebagai kepemimpinan moral dan intelektual. Kutipan dalam novel yang menunjukkan bentuk budaya dapat dilihat pada kutipan di bawah ini:

Pacaran merupakan aib di kampung. Apalagi di hutan. Kalau mereka tahu tentu akan menangkap kami. Lalu mereka memukuliku sebelum memandikan dalam kubangan. Syukur- syukur tidak dibotakin. Yang sering terjadi, mereka menganiaya orang yang berbuat mesum(Nur, 2017:120).

Kutipan di atas menggambarkan bahwa suatu budaya adat di perkampungan yang tidak memperbolehkan untuk pacaran apalagi sampai berbuat mesum karena itu merupakan aib bagi warga kampung. Kalau ada yang ketahuan melakukan perbuatan itu maka warga kampung akan menghukumnya entah itu dipukulin, diarak, sampai dinikahkan. Supaya sadar akan perbuatannya dan kampung terbebas dari aib yang akan terjadi.

(4) Kaum intelektual

Kaum intelektual dapat diartikan sebagai orang-orang yang memiliki fungsi sebagai organisasional dalam pengertian yang luas kebudayaan ataupun administrasi politik dan melakukan dobrakan ganda dalam pandangan umum terhadap intelektual. Dapat di lihat pada kutipan di bawah ini:

Semasa hidupnya bapak pernah bilang, kelak di surga, orang yang menolong akan didatangi orang yang ditolong. Yang dibantu di dunia akan membawa perhiasan dan segala benda-benda mulia dari surga untuk sang penolongnya. Manusia di bumi adalah belahan tubuh adam. Kita sama-sama anak bumi, pengatur sekaligus penjaga alam(Nur, 2017:69).

Kutipan di atas menjelaskan tentang kata - kata atau nasehat dari seorang Bapak yang selalu diingat oleh anaknya, bahwa manusia hidup haruslah senantiasa berbuat kebaikan kepada sesama orang yang membutuhkan. Kelak suatu saat di surga nanti orang yang kita bakal ditolong akan memhapiri untuk menolong dan membawa sifat atau amalan mulia dari surga.

(5) Negara

Negara adalah kompleks yang menyeluruh aktivitas-aktivitas teoritis dan praktis yang dengannya kelas penguasa 
tidak hanya membenaarkan dan mempertahankan dominasinya, melainkan juga berusaha memenangkan kesetujuan aktif dari mereka yang diperintahnya. kutipan yang menunjukkan hegemoni terhadap negara dapat di lihat pada kutipan di bawah ini:

Proyek jalan itu dikerjakan asal-asalan. Dikerjakan sejadinya saja. Cuma tiga puluh persen. Selebihnya, kontraktor membagi-bagikan dana untuk gerilya, tentara pemerintah, dan kepala pekerjaan umum. Tak lama jalan pun rusak. Yang tersisa sekarang hanya timbunan. Rakyat kena kibul lagi!.(Nur, 2017:123).

Dalam kutipan di atas, menggambarkan mengenai kecurangan yang dilakukan oleh kontraktor pengerjaan jalan yang dikerjakan dengan tidak serius, pkokonya asal jadi. Dana untuk pengerjaannya pun dikorupsi oleh kontraktor. Agar tidak ketahuan kontraktor tersebut membagikan hasil kosupsinya dengan tentara dan juga gerilya. Dan hasilnya pembangunan pun cepat rusak rakyat kena tipu dari pemerintah.

(6) Kepemimpinan

Kepemimpinan dalam hegemoni novel Seumpama Matahari identik dengan kemampuan para pejuang (pemberontak) atau lebih tepatnya seorang pejuang yang mempengaruhi dan memotivasi masyarakat Aceh untuk melakukan sesuatu sesuai tujuan bersama yaitu untuk bebas dari tindakan Tentara yang membabi buta.Hal itu tertulis pada kutipan di bawah ini:

cepat pergi! Kulindungi kalian!" perintah Maun, kembali menghujani tembakan yang tak tentu arah, perihal itu bukan dimaksudkan untuk membunuh, melainkan mengecoh lawan.

$\mathrm{Aku}$ dan basyah bangun dan lari mengendap-ngendap. Sementara arah tembakan peluru musuh terus menderu tak tentu arah, yang berarti lawan sedang dalam kebingungan (Nur, 2017:21).
Berdasarkan kutipan tersebut musuh telah menghujani dengan tembakan yang tak tentu arah dalam arti kalau pejuang tidak berhati-hati bisa terkena tembakan. Dalam hal ini sang pejuang maun terbentuk jiwa kepemimpinan yaitu mempengaruhi orang lain untuk melakukan sesuatu sesuai tujuan bersama. Pejuang maun perang dengan membalas tembakan musuh dimaksudkan agar musuh kebingungan.Dan menyuruh teman-temannya untuk menyelamatkan diri.

\section{SIMPULAN}

Berdasarkan hasil penelitian dan pembahasan tentang bagaimana hegemoni dalam novel Seumpama Matahari karya Arafat Nur. Dapat ditarik kesimpulan bahwa terdapat unsur-unsur hegemoni yang beroperasi di kota Aceh yang terjadi pada masyarakat Sipil. Wilayah tersebut melakukan cara tersendiri untuk mencapai tujuan hegemoni. Dapat terlihat bahwa masyarakat Sipil terkena hegemoni yang dilakukan oleh masyarakat politik yang sepenuhnya dikuasai oleh tentara pemerintah.Tentara sebagai oknum pemerintah menyalahgunakan kekuasaannya dengan tidak tepat dan berlindung kepada payung hukum Negara.Beberapa tokoh masyarakat politik tidak seluruhnya melakukan kekuasaan dengan tidak benar melainkan ada yang tetap patuh pada hukum Negara. Di dalam hegemoni novel Seumpama Matahari ini juga terdapat lima konsep kunci yang ada dalam teori Gramsci yaitu kebudayaan, hegemoni, ideologi, kaum intelektual, dan Negara yang di jelaskan dalam bait-bait yang ada di novel seumpama matahari beserta arti dari kandungannya yang berupa hegemoni.

\section{DAFTAR PUSTAKA}

Faruk. 2014. Pengantar Sosiologi Sastra. Yogyakarta: Pustaka Pelajar 
Kurniawan, Heru.2012. Teori, Metode, dan Aplikasi Sosiologi Sastra. Yogyakarta: Graha Ilmu

Patria, Nezar dan Ariaf, Andi.2015. Antonio Gramsci Negara dan Hegemoni. Yogyakarta: Pustaka Pelajar

Sugiyono, 2015.Metode Penelitian Kuantitatif, Kualitatif dan $R \& D$. Bandung: Alfabeta. 